\title{
Is early appendectomy in adults diagnosed with acute appendicitis mandatory? A prospective study
}

\author{
Salma Abu Foul, Ella Egozi, Ahmad Assalia, Yoram Kluger and Ahmad Mahajna*
}

\begin{abstract}
Introduction: Prompt appendectomy has long been the standard of care for acute appendicitis in order to prevent complications such as perforation, abscess formation, and diffuse purulent or fecal peritonitis, all resulting in increased morbidity and even mortality. Our study was designed to examine whether the time from the beginning of symptoms to operation correlates with the pathological degree of appendicitis, incidence of postoperative complications, or increased length of hospital stay.
\end{abstract}

Methods: A prospective study of 171 patients who underwent emergent appendectomy for acute appendicitis in the course of 2 years was conducted in a single tertiary medical center. The following parameters were monitored and correlated: demographics, time from the onset of symptoms until the arrival to the emergency department (patient interval (PI)), time from arrival to the emergency department (ED) until appendectomy (hospital interval $(H I)$ ), time from the onset of symptoms until appendectomy (total interval (TI)), physical examination, preoperative physical findings, laboratory data, pathologic findings, complications, and length of hospital stay.

Results: The degree of pathology and complications were analyzed according to the time intervals. The time elapsed from the onset of symptoms to surgery was associated with higher pathology grade $(p=0.01)$. We found that longer time from the onset of symptoms to hospital arrival correlates with higher pathology grade $(p=0.04)$, while there was no correlation between the hospital interval and pathology grade $(p=0.68)$. A significant correlation was found between the pathology grade and the incidence of postoperative complications as well as with increased length of hospital stay $(p=0.000)$.

Conclusion: Time elapsed from the symptom onset to appendectomy correlates with increased pathology grade and complication rate. This correlation was not related to the $\mathrm{HI}$. Since the $\mathrm{HI}$ in our study was short, we recommend an early appendectomy in adults in order to shorten the $\mathrm{TI}$ and the resulting complications.

Keywords: Acute appendicitis, Appendectomy, Postoperative complications

\section{Introduction}

Acute appendicitis is one of the most common surgical emergencies encountered in the ED. This condition may be associated with complications and significant rise in morbidity and even mortality if diagnosis and treatment are delayed [1]. Since the first appendectomy in 1883, early appendectomy has been advocated for acute appendicitis [2-4]. The course of conservative therapy of acute appendicitis with

\footnotetext{
* Correspondence: a_mahajna@rambam.health.gov.il

Department of General Surgery, Rambam Health Care Campus, The Technion - Institute of Technology, P.O. Box 9602, 31096 Haifa, Israel
}

antibiotics has been accepted in the pediatric population [5-7]. This concept of conservative therapy challenged the historical paradigm of emergent appendectomy in the adult population [8-10].

Despite the fact that conservative treatment with antibiotics has been shown to be safe also in adults, laparoscopic appendectomy remains the standard of care for acute appendicitis in adults [11-13]. This operation is frequently done by junior staff and can be performed in selected cases as an ambulatory surgery $[14,15]$.

The duration of the inflammation of the appendix is related to the risk of perforation [16-20]. Time periods

(c) The Author(s). 2019 Open Access This article is distributed under the terms of the Creative Commons Attribution 4.0 International License (http://creativecommons.org/licenses/by/4.0/), which permits unrestricted use, distribution, and 
between the onset of symptoms, medical assessment, and treatment are important. Previous studies revealed that in-hospital delay increases the risk of perforation in adults with appendicitis. Perforation was associated with a higher complication rate and increased length of hospital stay [21, 22]. On the other hand, in recent studies, delayed appendectomy, from 12 to $36 \mathrm{~h}$ from the symptom onset, was acceptable [3, 23-25].

The aim of this study is to determine the relationship between the time of the symptom onset to surgery (patient interval (PI) and hospital interval (HI)) in regard to pathological severity, complications, and hospital stay in patients with acute appendicitis.

\section{Methods}

A prospective study including all patients with the diagnosis of acute appendicitis at one tertiary medical center in the course of 2 years was designed. The study was approved by the Helsinki Committee at Rambam Medical Center. Exclusion criteria included patients younger than 16 years, patients who could not recollect the exact timing of symptom onset, and patients who had no appendicitis in the pathology examination. The diagnosis of acute appendicitis was confirmed by an ultrasound or computed tomography scan images prior to surgery in all patients.

A personal interview in regard to the time from the onset of symptoms to the hospital arrival (PI) was undertaken and recorded.

At surgery, the surgeon described the macroscopic appearance and graded the appendicitis, according to the scale presented by Ditillo and colleagues in 2006 [4]: simple appendicitis was graded G1, phlegmonous graded G2, gangrenous graded G3, and perforated graded G4. All specimens were examined by a pathologist.

Postoperative complication rate and hospital stay were recorded. Parameters were monitored including the time from hospital arrival to surgery (HI) and time from the symptom onset to surgery (total interval (TI)).

Antibiotics were administered for all patients immediately after the diagnosis of appendicitis. Patients with an intraoperative finding of intra-abdominal abscess or perforated appendicitis were given extended courses of antibiotics postoperatively. Appendectomies at our hospital are always initiated with a laparoscopic approach. Open conversion is done at any time when the surgeon judges that the laparoscopic procedure is unsafe or no longer possible.

\section{Statistical analysis}

Pearson's chi-square test was applied for categorical parameters, and the Kruskal-Wallis test and Mann-Whitney test for continuous variables. A $p$ value of $<0.05$ was considered statistically significant. Data was generated with
SPSS software (version 15.01.1, SPSS Inc., 2006). Descriptive statistics and graphical methods were used to characterize the date using Microsoft Office Excel.

\section{Results \\ Demographics}

One hundred seventy-one patients were included in our study: 112 men (65.5\%) and 59 women (34.5\%). Age ranged from 16 to 86 years, with a mean age of 33 years. There was no correlation between gender and the degree of pathology $(p=0.46)$, while advanced pathology grade was associated with advanced age $(p=0.001)$ (Table 1$)$.

\section{Relationship between physical examination parameters and the degree of pathology}

The mean temperature was $37.26^{\circ} \mathrm{C}$, ranging from 37.06 to $38.1^{\circ} \mathrm{C}$, with significant correlation to advanced pathological degree $(p=0.001)$. The highest mean temperature was $38.1^{\circ} \mathrm{C}$ noted at grade 3 .

The levels of WBC ranged from 12.7 to 14 thousand with a mean of 13.6. The correlation between leukocytosis and high pathological grade was significant $(p=0.028)$ as well. Advanced level was noted at grade 3 (Table 2).

Our data shows that the parameters of physical examination including abdominal tenderness and peritonitis were not correlated to the advanced degree of pathology. The percentage of abdominal tenderness among our patients ranged from 96 to $100 \%$, with a calculated $p$ value of 0.863 . While peritonitis was noted in 65 to $100 \%$, the calculated $p$ value was 0.29 (Table 2).

\section{Relationship between the time of surgery to the degree of pathology}

The prevalence of advanced pathology positively correlated with prolonged PI, ranging from 30.17 to $49.11 \mathrm{~h}$. For grade 1, the average time was $30.17 \mathrm{~h}$, while the average time for grade 4 was $49.11 \mathrm{~h}$, with a $p$ value of 0.04 .

The same positive relation was found for the TI, time range from 42.29 to $63 \mathrm{~h}$, while for grade 1, the interval noted was $42.29 \mathrm{~h}$, and for grade 4 was $63 \mathrm{~h}$, with a $p$ value of 0.01 .

At our study, the HI did not correlate with the degree of pathology; the average time for all grades was 12.37

Table 1 Relationship between demographic parameters and degree of pathology

\begin{tabular}{llllll}
\hline & G1 & G2 & G3 & G4 & Total \\
\hline $\begin{array}{l}\text { Age (average - } \\
\text { years) }\end{array}$ & 26.29 & 33.71 & 39.12 & 47.43 & 32.98 \\
Male (N) & 27 & 63 & 17 & 5 & 112 \\
Female (N) & 21 & 28 & 8 & 2 & 59 \\
Total & 48 & 91 & 25 & 7 & 171 \\
\hline
\end{tabular}


Table 2 Relationship between physical examination parameters and the degree of pathology

\begin{tabular}{llllll}
\hline & \multicolumn{6}{l}{ Degree of pathology } \\
\cline { 2 - 6 } & G1 & G2 & G3 & G4 & $p$ value \\
\hline Number of patients & 48 & 90 & 25 & 7 & \\
Fever $\left({ }^{\circ} \mathrm{C}\right)$ & 37.06 & 37.11 & 38.1 & 37.26 & $<0.001$ \\
WBC & 12,700 & 13,500 & 14,060 & 13,590 & $=0.028$ \\
Abdominal tenderness (\%) & 96 & 98 & 96 & 100 & $=0.863$ \\
Peritonitis (\%) & 65 & 68 & 72 & 100 & $=0.293$ \\
\hline
\end{tabular}

NR number of patients, ${ }^{\circ} \mathrm{C}$ Celsius

h, range from 12.13 to $13.86 \mathrm{~h}$, with a $p$ value of 0.68 (Table 3).

Relationship between postoperative hospital stay, complication, and the degree of pathology

Hospital stay and the rate of complication increased according to higher pathological degree with a $p$ value of 0.000 for the two parameters (Table 4). For grade 1 , the complication rate was $2 \%$, increased according to the advanced grade, reaching $100 \%$ for grade 4 . For hospital stay, the average days in the hospital for grade 1 were 3.21 days, while 9 days for grade 4 .

\section{Discussion}

The timing of the onset of the symptoms of appendicitis is important in deciding when to perform acute care surgery. Delayed surgery from the symptom onset is associated with worse outcomes for the vast majority of the surgical emergencies [25-27]. As noted in retrospective studies conducted in the adult population, acute appendicitis is a time-dependent disease in regard to severity and complication rate [6]. Delay in the overall timing of treatment increased the risk of progression of pathology and postoperative complications [4]. Such findings are contradicted with studies on child population, suggesting antibiotic treatment as a mean of therapy [5-7]. In adults, appendectomy remains the most effective and safe treatment for acute appendicitis when compared with antibiotic treatment [2, 28-30]. The urgency of the operation is still controversial.

Table 3 Relationship between the timing of surgery and degree of pathology

\begin{tabular}{llllll}
\hline & G1 & G2 & G3 & G4 & $p$ value \\
\hline PI (h) & 30.17 & 31.25 & 47.76 & 49.11 & $=0.04$ \\
$\mathrm{HI}(\mathrm{h})$ & 12.13 & 11.8 & 11.72 & 13.86 & $=0.681$ \\
$\mathrm{TI}(\mathrm{h})$ & 42.29 & 43.05 & 59.48 & 63 & $=0.01$ \\
\hline
\end{tabular}

$P /$ patient interval, $H$ I hospital interval, $T$ I total interval, $h$ hours
Table 4 Relationship between postoperative hospital stay and complications

\begin{tabular}{llllll}
\hline & G1 & G2 & G3 & G4 & $p$ value \\
\hline Number of patients & 48 & 90 & 25 & 7 & \\
Hospital stay (days) & 3.21 & 3.6 & 5.08 & 9 & $=0.00$ \\
Complications (\%) & 2 & 8 & 48 & 100 & $=0.00$ \\
\hline
\end{tabular}

In accordance to known data, at this study, the main population was young men, with the mean age of 33 years old. A positive correlation was found between the advanced age and advanced degree of pathology. This relation might be contributed to the longer time to diagnosis in the older population known from the different octogenarian studies; this was not monitored at the current study and needs further research.

Pathological degree correlates strongly with prolonged time from the symptom onset to the hospital arrival and from the symptom onset to appendectomy; such findings correlate with previse conclusions of retrospective studies [28, 29]. Suggesting the need for expeditious appendectomy once the diagnosis was confirmed.

The hospital interval, from diagnosis to surgery, was not found to be a statistically significant parameter at the current study, in contrast with previous studies $[4,21]$. Such difference may be contributed to relatively short time from diagnosis to surgery at our center (11.8-13.8 h) which is at the lower time limit suggested in the literature, 12-36 $\mathrm{h}[3,23]$. It might be also contributed to the prospective nature of our study. Though the in-hospital time was not found to be a factor of pathological severity at this study, the debate about the acceptable time is yet to be determined.

Although PI showed statistical significance, it is not easy to shorten this time period directly. Therefore, it is recommended that clinicians focus on shortening the total interval. Reducing PI might be accomplished through education and dissemination of publicity.

According to our study, higher pathological degree was in correlation to a longer hospital stay and to a higher rate of complication. Considering our data which demonstrates positive correlation between advanced pathology grade and the total time interval and the patient interval, an urgent appendectomy is recommended, though such surgery might be delayed according to the hospital capability while the patient is hospitalized with antibiotic therapy awaiting surgery.

Surprisingly, at our study, abdominal tenderness and signs of peritonitis were not correlated with the degree of pathological severity, in contrast to previous studies [4]; the deference might be the prospective nature of this study. 


\section{Conclusion}

Based on the positive relation between the onset of symptoms to appendectomy, pathological severity, and complication rate, we advise early appendectomy according to the hospital capability; these findings are consistent with the conclusions of the World Society of Emergency Surgery study group initiative [31]. A largesample prospective study should be conducted to set the optimal time for surgery since the diagnosis of appendicitis.

\section{Abbreviations \\ ED: Emergency department; HI: Hospital interval; PI: Patient interval; TI: Total} interval

\section{Acknowledgements}

Not applicable.

\section{Funding}

There is no funding to declare.

\section{Availability of data and materials}

Please contact author for data requests.

\section{Authors' contributions}

SAF participated in preparing the literary background for the study and drafted the manuscript. EE participated in data collection and performed the statistical analysis. AA helped in drafting the manuscript. YK participated in the study design and performed critical revision of the manuscript. AM conceived the study, participated in its design and coordination, and helped in drafting the manuscript. All authors read and approved the final manuscript.

\section{Ethics approval and consent to participate}

The study was approved by the Helsinki Committee at Rambam Medical Center, Haifa, Israel. The committee's reference number is 0571-18-RMB.

\section{Consent for publication}

Not applicable.

\section{Competing interests}

The authors declare that they have no competing interests.

\section{Publisher's Note}

Springer Nature remains neutral with regard to jurisdictional claims in published maps and institutional affiliations.

Received: 13 November 2018 Accepted: 28 December 2018

Published online: 11 January 2019

\section{References}

1. Storm-Dickerson TL, Horattas MC. What have we learned over the past 20 years about appendicitis in the elderly? Am J Surg. 2003;185(3):198-201.

2. Johan S, Staffan E, Ingermar N, et al. Appendectomy versus antibiotic treatment in acute appendicitis. A prospective multicenter randomized controlled trial. World J Surg. 2006;30:1033-7.

3. Frederick $E$, Gabriel R, Leslie $D$, et al. Ideal timing of surgery for acute uncomplicated appendicitis. N Am J Med Sci. 2013;5(1):22-7.

4. Ditillo MF, Dziura JD, Rabinovici R, et al. Is it safe to delay appendectomy in adults with acute appendicitis? Ann Surg. 2006;244(5):656-60.

5. Yardeni D, Hirschl RB. Delayed versus immediate surgery in acute appendicitis: do we need to operate in the middle of the night? J Pediatr Surg. 2004; 39:464-9.

6. Surana R, Quinn F, Puri P. Is it necessary to perform appendectomy in the middle of the night in children? Br Med J. 1993;306:1168

7. Bachoo P, Mahomed AA, Ninan GK, et al. Acute appendicitis: the continuing role for active observation. Pediatr Surg Int. 2001;17:125-38.

8. Stahfeld K, Hower J, Homitsky S, Madden J. Is acute appendicitis a surgical emergency? Ann Surg. 2007;73:626-9.
9. Kearney D, Cahill RA, O'Brien E, et al. Influence of delays on perforation risk in adults with acute appendicitis. Dis Colon Rectum. 2008;51:1823-7.

10. Jae Min L, Boem Seok K, Young Jin P. Is a one night delay of surgery safe in patients with acute appendicitis? Ann Coloproctol. 2018;34(1):11-5.

11. Hansson J, Korner U, Khorram-Manesh A, Solberg A, Lundholm K. Randomized clinical trial of antibiotic therapy versus appendectomy as primary treatment of acute appendicitis in unselected patients. Br J Surg. 2009;96:473-81.

12. Harnoss JC, Zelienka I, Probst P, Grummich K, et al. Antibiotics versus surgical therapy for uncomplicated appendicitis: systematic review and meta-analysis of controlled trials (PROSPERO 2015: CRD42015016882). Ann Surg. 2017;265: 889-900.

13. Sartelli M, Viale $P$, Catena F, Ansaloni L, et al. WSES guidelines for management of intra-abdominal infections. World J Emerg Surg. 2013:8:3.

14. Lefrancois M, Lefevre JH, Chafai N, Pitel S, Kerger L, et al. Management of acute appendicitis in ambulatory surgery: is it possible? How to select patients? Ann Surg. 2015;261:1167-72.

15. Gignoux B, Blanchet MC, Lanz T, et al. Should ambulatory appendectomy become the standard treatment for acute appendicitis? World J Emerg Surg. 2018;13:28

16. Eldar S, Nash E, Sabo E, et al. Delay of surgery in acute appendicitis. Am J Surg. 1997;173:194-8.

17. Temple CL, Huchcroft SA, Temple WJ. The natural history of appendicitis in adults. A prospective study. Ann Surg. 1995;221:278-81

18. Maroju NK, Robinson Smile S, Sistla SC, et al. Delay in surgery for acute appendicitis. ANZ J Surg. 2004;74:773-6.

19. Hardin DM Jr. Acute appendicitis: review and update. Am Fam Physician. 1999;60:2027-34.

20. Papandria D, Goldstein SD, Rhee D, Salazar JH, Arlikar J, Gorgy A, Ortega G, Zhang Y, Abdullah F. Risk of perforation increases with delay in recognition and surgery for acute appendicitis. J Surg Res. 2012. https://doi.org/10.1016/ j.jss.2012.12.008

21. Abou-nukta F, Bakhos C, Arroyo K, et al. Effects of delaying appendectomy for acute appendicitis for 12 to 24 hours. Arch Surg. 2006;141(5):504-6

22. Mirjam B, Florian SG, Sonja A, Rolf K, Urs M, Urs Z. In-hospital delay increases the risk of perforation in adults with appendicitis. World J Surg. 2011:35:1626-33.

23. Kim M, Kim SJ, Cho HJ. Effect of surgical timing and outcomes for appendicitis severity. Ann Surg Treat Res. 2016:91(2):85-9.

24. Eko FN, Ryb GE, Drager L, Goldwater E, Wu JJ, Counihan TCN. Ideal timing of surgery for acute uncomplicated appendicitis. Am J Med Sci. 2013;5(1):22-7.

25. Abou- Nukta F, Bakhons C, Arroyo K, Martin J, Reinholds R, Ciadiello K. Effect of delaying appendectomy for acute appendicitis for 12-24 hours. Arch Surg. 2006;141(5):504-6.

26. Svanes C, Lie RT, Svanes K, Lie SA, Soreide O. Adverse effects of delayed treatment for perforated peptic ulcer. Ann Surg. 1994:220:16875.

27. Surapaneni S, Rajkumar S, Reddy AVB. The perforation operation time interval; an import ant mortality indicator in peptic ulcer perforation. J Clin Diagn Res. 2013;7:8802.

28. Kirby A, Hobson RP, Burke D, et al. Appendectomy for suspected uncomplicated appendicitis is associated with fewer complications than conservative antibiotic management: a meta-analysis of post-intervention complications. J Inf Secur. 2015;70(2):105-10.

29. Podda M, Cillara N, Di Saverio S, et al. Antibiotics-first strategy for uncomplicated acute appendicitis in adults is associated with increased rates of peritonitis at surgery. A systematic review with meta-analysis of randomized controlled trials comparing appendectomy and non-operative management with antibiotics. Surgeon. 2017;15(5):303-14

30. Poillucci G, Mortola L, Podda M, et al. Laparoscopic appendectomy vs antibiotic therapy for acute appendicitis: a propensity score-matched analysis from a multicenter cohort study. Updat Surg. 2017:69(4):531-40.

31. Kluger $Y$, Ben-Ishay $O$, Sartelli M, et al. World Society of Emergency Surgery study group initiative on Timing of Acute Care Surgery classification (TACS). World J Emerg Surg. 2013;8(1):17 